\title{
Appraisal of Vernacular Stone Housing Typology of Tigrai, Ethiopia
}

\author{
Samuel Bekele Jetie \\ School of Architecture and Urban Planning, Ethiopian Institute of Technology, Mekelle University, Mekelle, Ethiopia
}

\section{Email address:}

archsami@yahoo.com, archsami2005@gmail.com

\section{To cite this article:}

Samuel Bekele Jetie. Appraisal of Vernacular Stone Housing Typology of Tigrai, Ethiopia. International Journal of Architecture, Arts and Applications. Vol. 5, No. 1, 2019, pp. 1-9. doi: 10.11648/j.ijaaa.20190501.11

Received: December 15, 2018; Accepted: January 14, 2019; Published: January 31, 2019

\begin{abstract}
Tigrai vernacular housing mainly characterized by a stone architecture called hidmo, which is an astonishing feature of the country and the region. The hidmo house does not only mean a flat roofed vernacular house, but it is becoming an architectural style since thousands years ago at the beginning of Aksumite civilization. The objective of this paper is to appraise the vernacular housing typology and their spatial relationship in Tigrai, Ethiopia. Using field visit, observation, non-structured interview, cross-checking different data sources are used for qualitative data collection and the collected data are synthesized and categorized. According to the research study the Tigrai vernacular housing has mainly three housing typology namely, the Tigrai farmer house commonly called hidmo house, Tigrai chief house that is housed for the rich, clerks and leaders and the third is Agudo dwelling unit a house for common people. In the Tigrai farmer house we could have variations and labeling such as Merebae and Sekela house. All the housing typology have rectilinear shape, form and use the same building material that is a stone wall, mud and timber roof, but Agudo dwelling unit and Tigrai chief house have circular plan and conical thatched roof. The very nature of the Tigrai housing typology has the potential to respond the sustainability of the climate and the availability of abundant materials, mainly stone and the 'Monkey head construction' system.
\end{abstract}

Keywords: Ethiopia, Hidmo, Housing, Stone Architecture, Tigrai, Vernacular

\section{Introduction}

The term vernacular originates from the Latin word vernaculus which means local, natural or original developed from Verna, meaning "native slave" or "home-born slave". The vernacular architecture is the amazing skill shown by primitive and peasant builders in dealing with climatic problems, and their ability to use minimum resources for maximum comfort. [9]

Vernacular architecture is sometimes called architecture without Architects reveals the combination of local climate conditions, locally available materials, simple construction techniques, living style, traditions and socio-economic conditions of the region.[4], vernacular building is human constructs that are the results of the relationships among ecological, economic, material, and social factors. Due to the fact that vernacular architecture has evolved through trial and error methods, vernacular buildings and site planning depend on substantial experience, surrounding conditions, and local materials such as adobe, stone and timber. Specifically, vernacular architecture takes attention in terms of its continuity. Thus, it can be seen as the essence of sustainability with its inherent characteristics. Moreover, vernacular settlements are often considered as the predecessors of sustainable built environments.

Vernacular architecture characterizes houses made from local available materials, shaped by local climate and reflects the regional culture and traditions. It serves as a mirror of society and the needs of human beings at certain times. Vernacular buildings represent ingenious and considerable technical innovations and perform spectacular handicraft work. The construction techniques and forms were evolving over thousands and hundred years by generations to meet their everyday needs. [2]

The Tigrai region is a home of mesmerizing vernacular architectural such as hidmo housing and Monkey head construction system. The climate and topography of Tigrai is found in the arid and semi-arid zone of Ethiopia, where it is mostly hot and dry. In response to the harsh diurnal 
temperature differences, thick, stocky stone masonry construction is employed. Vernacular architecture is impressively rich of basic solutions with sustainable issues for its environment. In this paper, the vernacular stone housing typology and with spatial relationships will be appraised and described briefly.

\section{Background of the Study Area}

Ethiopia has rich in ancient human history and the human settlement started from the oldest civilization in the Da'mat dynasty's capital city of Yeha and this was considered as the first human settlement (urban area) in the Tigrai region and the country in general. Tigrai region is one of the nine national regional states in Ethiopia located in the top northern part, has a rich in history, archeology, and astonishing vernacular architecture especially the stone housing architecture. Tigrai region is one of the oldest civilizations with more than 3000 years has amazing history and architecture landscape. [13]

Tigria lies at the top northern part in the chain of the highlands of Ethiopia. Tigria is located in the longitude of $12^{0} 15-4^{0} 57$ and latitude of $36^{0} 27-39^{0} 59$, the altitude of the region rise from 600 to $2,700 \mathrm{~m}$ above sea level and spread over an area of $80,000 \mathrm{sq} . \mathrm{km}$. The temperatures in the Tigrai region range from 12 to 34 degrees Celsius and the mean temperature is always higher than 21 degrees Celsius. Climatic data states that the rains are mostly received during June to September ordinarily called summer season and annual rainfall is nearly up to $450-980 \mathrm{~mm}$ and it becomes scanty after mid of September and stops by the ahead of October. Tigria experiences a semi-arid to arid conditions in Tropical season where it is mostly hot and dry winter and rainy summer. [14]

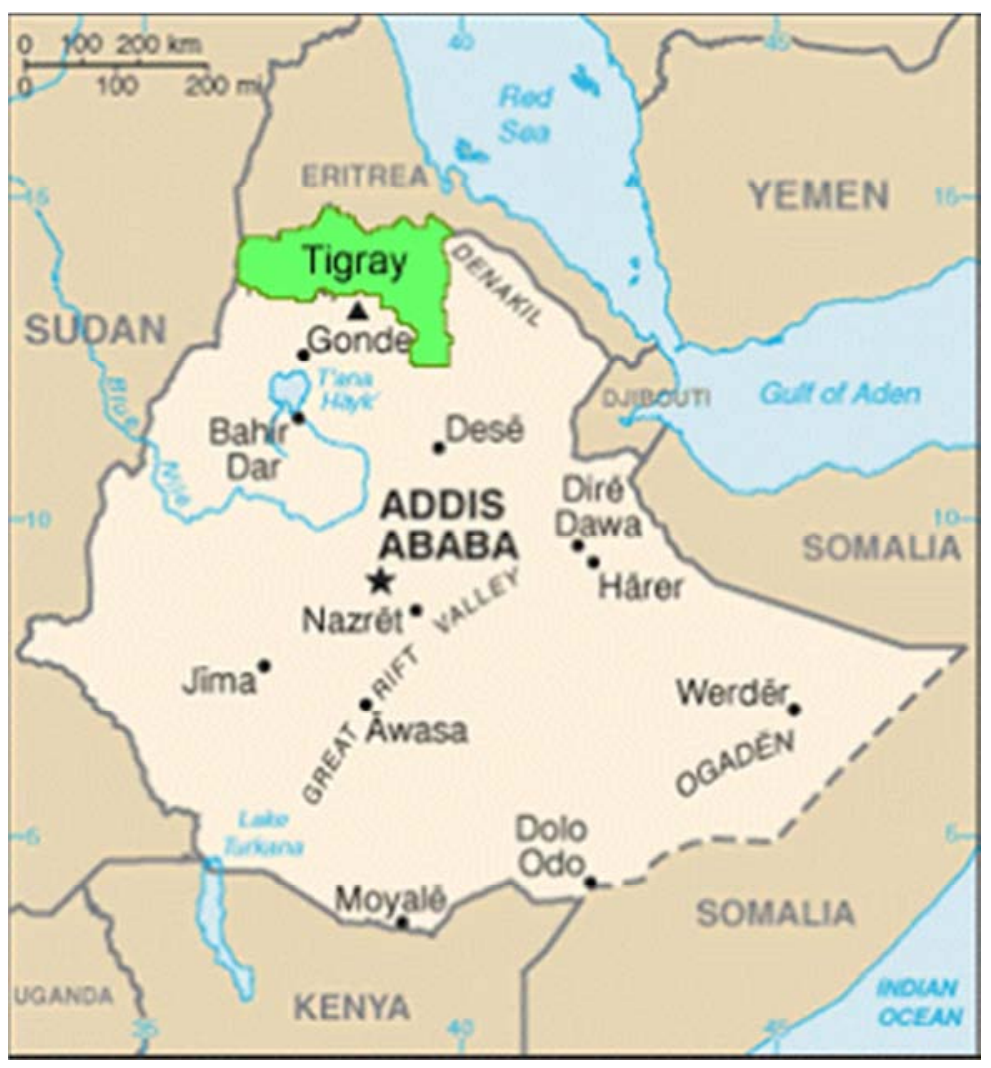

Figure 1. Map of the study area: Tigrai National Regional State (TNRS) in Ethiopia.

One of the courtesies of the old Christian civilization of the Tigrai is the mesmerizing architecture of housing which commonly called hidmo house. Tigrai houses have been guilt for thousands of years with not much change. Though, the climate is changing in recent times. Tigrai inhabitants constructed adaptable houses that took these climatic and topographic conditions into account. The typical characteristics of Tigrai housing, especially climatic features can be identified in terms of site layout, passive design, material and structure. Hence, the prime requirement of the housing buildings is to reduce the heat gain in harsh winter and to increase the ventilations.

\section{Methods}

The main goal of the research is to explore, describe or appraise the less known vernacular housing typology of Tigrai, Ethiopia. hence, information was obtained through two parallel processes: fieldwork for qualitative survey involving direct observation in the villages and a theoretical and historical analysis through literature review survey of books, articles, library and internet. Both these aspects were continually developed at every phase of the investigation. The data were collected via: 
(1) On site physical, sketch, photograph and video surveys of existing vernacular buildings is made, allowing a qualitative statistical analysis of the different types of vernacular housing/architectures and helps to analyze space relationships and physical artifact, this could comprise of material being used and housing typology.

(2) Non-structured interviews with local stone-house master builders, discussion with experts such as architects and engineers and post occupancy who are the sole patent owner of the design and construction techniques. This process allowed the detailed understanding of the housing portrayal, housing shape, source of building material, space arrangement and the construction techniques and the post occupancy evaluations provide an indication of the major successes and failures in a building's sustainability issues and building performance.

(3) Cross-checking different data sources to verify and validate the collected information.

The first step in the evaluation and comparison after data collection is to categorize the housing typology exploring the general features such as the plan, shape, form, geometry, spatial organization, roofing type or style, number of stories and its building materials and construction techniques is the studied variables.

\section{Typological Analysis of Tigrai Vernacular Stone Architecture/House}

\subsection{Spatial Analysis of the Architectural Housing and Its Main Components}

Vernacular architecture of Tigrai, northern Ethiopia, mostly related to the stone housing construction. Traditional dwellings and their method of construction was certainly worth to note here because the construction systems of the Tigrian vernacular houses were more than a thousands years old with not much change and still in use in the rural areas.
The architectural spaces forming the Tigrai vernacular stone house can be divided into three patterns of spaces: These are the open spaces, semi-open spaces and closed spaces.

\subsubsection{Open Spaces}

In the Tigrai vernacular housing architecture, there are important open spaces that can play in the lives of the dwellers of the houses. These areas include: courtyard (dembe) and the flat hidmo roof terrace.

Courtyard (dembe) which most of the time has a central location and important open space which makes the house to breathes healthy, increases thermal comfort and connects the closed and semi-open spaces. The courtyard is commonly used as a cattle area and sometimes used as an events, organizing area for religious fiestas and it is the main source of light and ventilation.

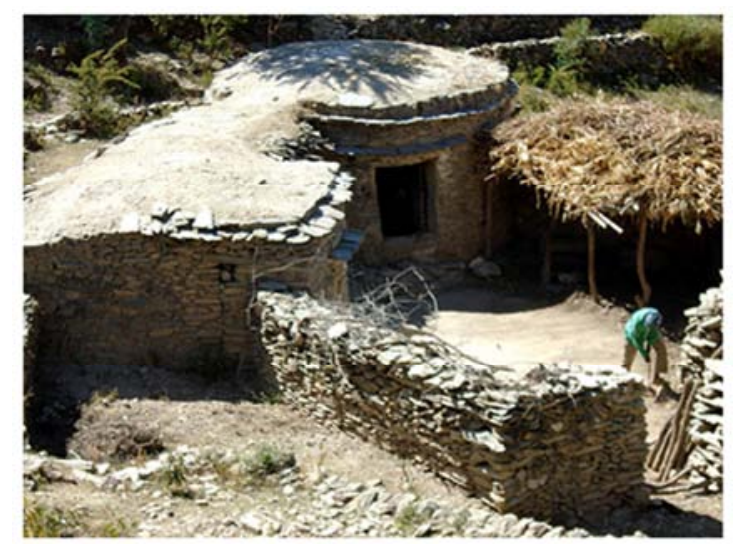

Figure 2. Hidmo house with its central courtyard.

Flat hidmo roof terrace (nahsi) is another special open space with staggering skyline has created by elevation difference in rooms and commonly used as grain and/or straw store or if the site allows or by forming outside stone steps it will serve as a sheep and goat sleeping area.

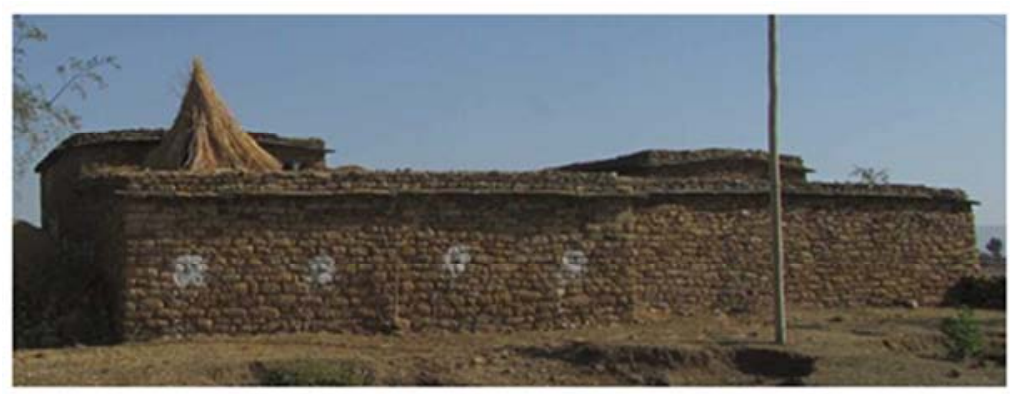

Figure 3. Typical hidmo house.

\subsubsection{Semi-Open Spaces}

An intermediate space between open and closed spaces in the Tigrai vernacular house, there is an intermediate space or half space covered areas called semi-open spaces and the space defined by wooden column and flat hidmo roof. These spaces play an important role in creating a visual connection between the open and closed spaces and the nature of lifestyle is highlighted. Areas covered include: entrance, porch, and pergola (Afgebela).

Entrance is defined by stone walls and wooden door frame helps to direct towards the porch which is a transitional space to the central courtyard (open space). The double wooden doors and each door have metal percussion. 


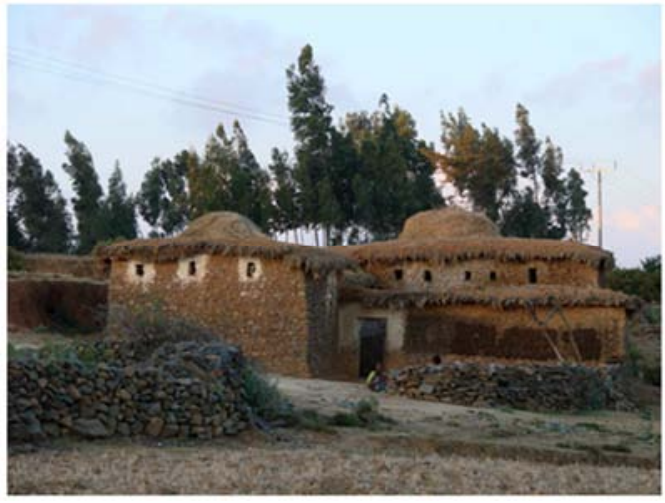

Figure 4. Hidmo house.

The Porch like space is a semi-open space area which defines its three sides by stone walls and flat roof called the hidmo, used as a passage and helps to link the inside main open space courtyard and outside premises.

Pergola (Afghebela) it is one of semi-open spaces with a well-defined space has different dimensions according to the level of the economy, is used to create shaded and cool living spaces during the day. This space is open on one side and is surrounded by a stone wall, wooden columns and has flat hidmo roof. Some part of the space is for domestic animal and the other part of it is used for the winter sleeping of family members. This is a space where the traditional farming materials and tools have placed. The Afgebela is commonly used as a cattle, sheep and goat area and sometimes used as an events organizing area for religious fiestas.

\subsubsection{Closed Spaces}

The main livable space of dwellers is accompanied of three architectural elements: flat roof or hidmo, stone wall, earthen floor and all components such as wooden doors, small windows and mud made furniture. The main hidmo house includes one story and sometimes two story house has inside two adjacent spaces:

Mediribet: this is the core of closed space with a flat mud roof the style called hidmo roof, thick stone wall and earthen floor. Though the main function is for living, dining and sleeping there is an inside space defined by local grain silo (kofo/godo) called Wushate commonly used to store grain and other expensive items.

Wushate is a space within a space which is found inside the closed space of the main room (Mediribet).

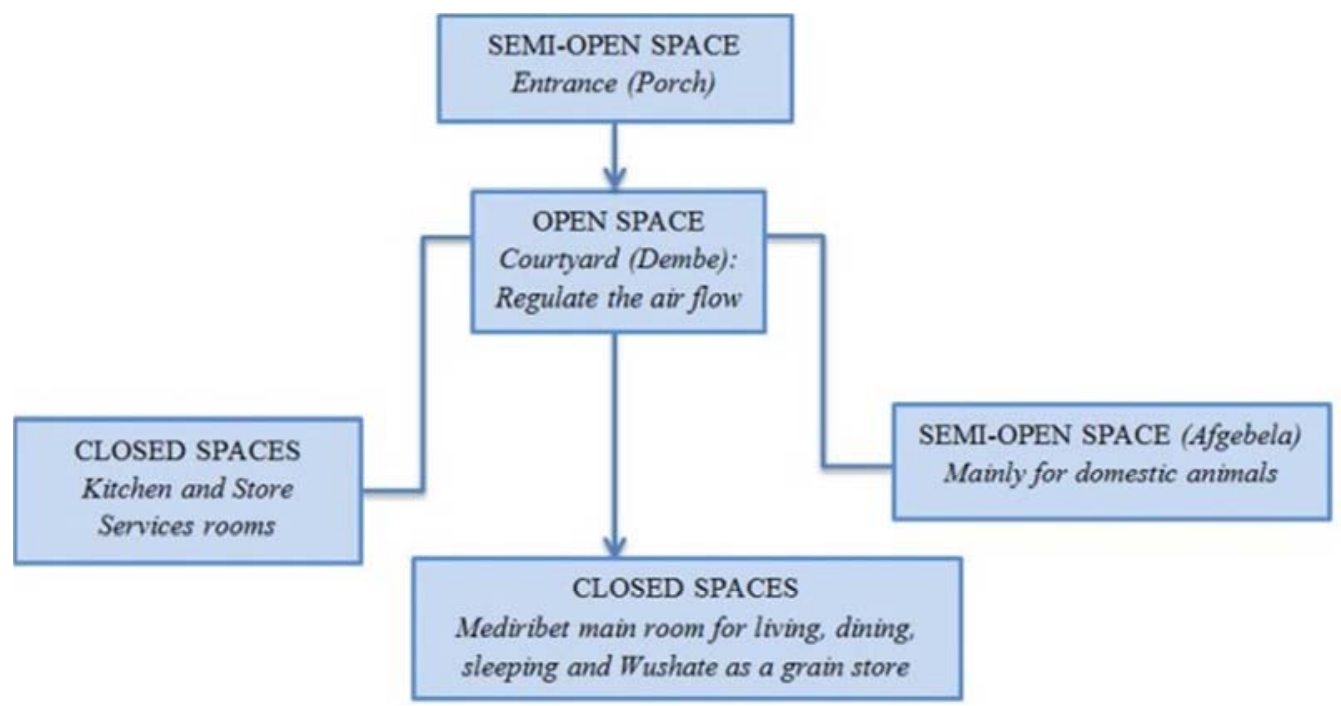

Figure 5. Spatial and Functional relationship of Tigrai vernacular housing spaces (Source author).

\subsection{Vernacular Housing Typology (Stone Architecture)}

According to the principles and elements of architectural design (plan, shape, pattern and form), uses of construction materials, construction techniques and socioeconomic class of the dwellers, Tigrai vernacular stone house/architecture have the following distinct typologies:

1. Hidmo dwelling unit commonly called the Tigrai farmer house and has different varieties such as Merebae (pitched shed roof type) and Sekela (attic floor type).

2. Tigrai chief house and.

3. Another special typology is the circular shape in its plan called Agudo.

\subsubsection{Hidmo Dwelling Unit/ Tigria Farmer House (Type A)}

Hidmo is a substantial structure with a simple unit rectangular in plain and flat roofed dwelling and mostly known and considered as an architectural style made-up from the abundant stone, mud, tree branches, timber/wood, soil/earth and slate. Hidmo is found only in the Northern Ethiopian highlands explicitly in the Tigrai National Regional State (TNRS) and this dwelling unit is common to all farmers and literally called Tigria farmer house.

The Tigrai farmer house has a basic construction structural system such as wooden lintel, beam and column. An extended roof at the front acting as a vernacular semi open space known as "Afgebela/Gebela" in a modern space like a pergola. The widespread construction of Hidmo house incorporates tree trunks supporting the 
weight of the roof, which constructed from a layer of tree branches, layer of mud, bounded by stone and then slate and the massive stone wall is often closer to the more than half meter thick. The pillars in hidmo house are made of strong juniper or olive tree trunks and rarely eucalyptus trunk are used to separate the internal space of the rooms and the area between the two consecutive pillars called "maybet".
Basically the Hidmo house is usually separated into five sections or spaces: The living room area "mederibet" there are strong family ties, The kitchen "utone" a furnace for baking traditional staple bread of Ethiopia called enjera and grain store "Wushate" defined by grain silo kofo/godo a string of built in grain stores, The cattle/livestock area "Gebela or afgebela" and the courtyard area "dembel mereba".

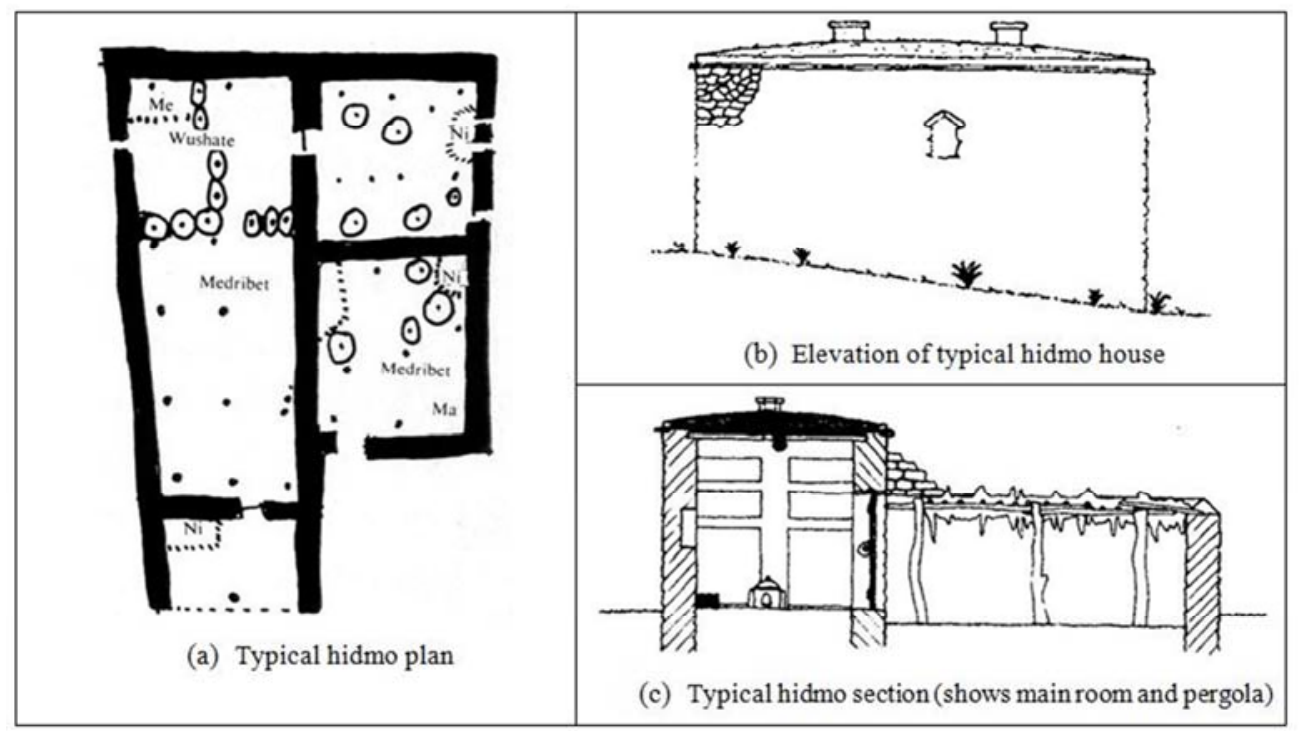

Figure 6. Typical Tigrai Hidmo stone house.

Hidom is not only an important structure, but it is rather an architectural style and movement for a thousands years with little change. Hidmo construction expressed typically by Fishbone shaped flat roof made of timer ceiling, mud and slate (as eave) and the name is literally linked with a flat roof and act as a general name for Tigria vernacular architecture (stone house) and the 'hidmo housing style' has a standard architecture through the region and expressed by the stone building material and 'Monkey head construction techniques.' [3].

The Tigrai farmer house demonstrates the common social and architectural characteristics of Tigria with its inhabitant's similar extroverted life style, economical functions and natural characteristics of the environment. It has survived through the impact of physical factors as the topography, climate and availability of water sources, agricultural areas and building materials; as well as socio-cultural factors as the village, social life and customs. This primal type is the result of a collective design language which has been structured and modified by the local master builders and the people.

The Hidmo rectangular unit varies its size and dimension because of many reasons. The ceiling height for the main living room (medribet) is around 3.60 meters, and the height of the one floor mass from the ground to the roof level is approximately 3.20 meters, in varying sizes between 3.00 and 4.00 meters. In general the basic architectural elements of the hidmo dwelling are classified as flat roof, afgebela/gebela, entrance, chimney, small window openings, functional room, courtyard and thick wall. The shape, dimension and place of these features in the overall design are determined by four basic factors such as availability of construction materials, social-economy/class, climate and function.

According to Table 1, stone and timber/wood as construction materials basically determines the size, shape and form, the climate determines basically the place of entrance, openings and afgebela/gebela, and the functions determine the arrangements of the hidmo dwelling rooms.

Table 1. Elements and determinates for elements of hidmo house.

\begin{tabular}{|c|c|c|c|c|}
\hline Elements & Construction material & Socio-economic class & Climate & Function \\
\hline Entrance $($ Beri $)$ & & & Determine direction & \\
\hline Courtyard (Dembe) & & Determine size & Determine size & Determine arrangement \\
\hline Rooms (Medriebet) & Determine form, shape and size & Determine number and size & Determine direction & Determine arrangement \\
\hline Pergola (Afgebela/gebela) & Determine size & Determine size & Determine direction & \\
\hline Wall (Mendek) & Determine form and size & Determine clearstory & & Determine arrangement \\
\hline Roof (Nahsi) & Determine form and size & Determine type & & Determine arrangement \\
\hline Opening (Finistra) & Determine shape & & Determine form and size & \\
\hline
\end{tabular}




\subsubsection{Variation of Hidmo Dwelling Unit}

There are varied combinations of hidmo dwelling units or Tigrai farmer house which are diversified according to the rising demand for closed space and lack of available natural building material especially timer/wood. Moreover, these are the types transformed in terms of time and changing lifestyles, especially in the last decade with the impact of the national economic growth. The improvement on the infrastructure facilities increased the social and economic integration and resource mobilization.

The Hidmo dwelling unit can be grouped according to its number of stories as one floor, one floor with basement and two floors. The examples with a basement floor are usually erected on the sloped grounds. Furthermore the rural dweller may prefer to build a basement floor in order to store wood, goods, big potteries and for keeping animals.

\section{i. Merebae House (Type B)}

Nowadays, the earthen flat roofs is going to be swallowed by the pitched conventional material called corrugated galvanized iron sheet roofs because it became possible for the rural dweller to buy iron sheet roof and the Merebae created as a result of this economic transformation. Merabae is modified architectural space of hidmo and it is almost similar as of the Tigrai farmer house and agudo with all its material (stone, mud and earth) and construction techniques but the only basic difference in the roofing shape, style and material. The roofing style is either shade or gabled and the space commonly used as living, guest room, dining area, sleeping and kitchen area.

\section{Ii. Sekela House (Type C)}

Sekela is another part of the hidmo housing unit looks like an attic floor has additional spaces for sleeping and store area. The sekela house unlike the typical Tigrai farmer house or hidmo and agudo housing typology found in large housing families and use the same building material and construction techniques as of hidmo and agudo dwelling unit, however unlike hidmo houses the roofing material is thatched.

\subsubsection{Tigrai Chief House (Type D)}

Tigrain chief house is a two story building has the same roofing shape that is conical as of Agudo and Sekela and the same building material and construction techniques of wall as of agudo, sekela and hidmo houses which are the widely used housing units by the farmer. Unlike the Agudo and hidmo housing, which are common to ordinary farmers, Tigrai chief house with the amount of material and specialized detail requirement make it a very complicated and very expensive prospect and because of this the Tigrai chief house is a residence for the rich, governor (chikashum), high level priest and soldiers around the cradle of the Ethiopian civilization called Akum, where the people are proponent of the early Ethiopian Christian culture hence the Tigrai chief house is architecture for the rich. [10]

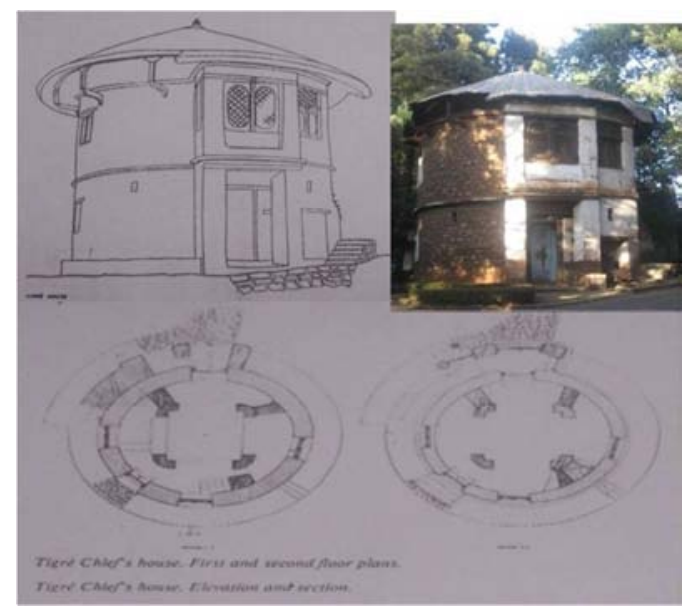

Figure 7. Tigrai Chief House.

Some of the common features of Tigrai chief house:

a). Surface quality: the surface could have rough texture or be white washed massing.

b). Shape: the long two storied cylinder is topped by a very wide almost flat cone like roofs with extending eaves.

c). Spatial concepts: the space seems to be very central in nature.

d). The climate: arid climate has forced masonry construction of a thick stone wall.

e). The materials: Blackstone (basalt, found abundantly in the Tigrai provinces) is used for foundations. Trachyte, a soft, greyish rock is used for the main wall. Mud (Chika) is used as mortar.

f). The windows, doors, lintels, floors and ceilings are carved out of wood and make up the main expenses for these houses.

g). Construction: The foundation trenches are dug with generous dimensions and filled in with basalt which doesn't absorb water: Simple masonry construction is used for the walls with ends at every floor with a shelf to stop rain from washing down the walls and damaging the Mud (Chika) mortar.

\subsubsection{Agudo Dwelling (Type E)}

The Agudo is more modes dwelling typology found in most areas of Tigrai like that of the Tigrai farmer house or hidom house. Agudo house has circular plan and measuring approximately three meters in a diameter. The wall of Agudo is made up totally from stone and mud, with a conical thatched roof. The Agudo dwelling unit has less number of rooms than the typical hidmo house and because of the economical affordability the weaker economical section of the farmers commonly uses this housing typology. [6]

\section{Results and Discussions: Summary of the Features of the Vernacular House}

The Tigrai vernacular typology houses have the following predominant architectural features:

Shape of the plan: The Tigrai vernacular house has 
rectilinear and sometimes a hybrid of rectilinear and circular in shape. Other than the Agudo and Tigrai chief house all the rooms in the Tigrai farmer house or Hidmo house are rectangular rooms. The room could classify according the functions into two chambers. The chamber closest to the entrance is used for service functions as cattle/livestock area and straw storage. The other one side of the gate comprises the main functional rooms which are the heart of the dwelling with its most common use of the functions as cooking, eating, sitting, sleeping and grain storage. This living part is usually has a higher ceiling height than the first chamber. Generally the Tigrai vernacular house has simplistic shapes and form with no ornamentation makes the dwelling unit very functional.

Number of stories/s: except the Tigrai chief house which is two stories the rest housing typology are one story buildings. In cases of the double story houses the upstairs would be used as a bedroom, leaving room or guest room. However, in some cases, if the topography and economy allows the Tigrai farmer house and Sekel house also built in two stories.

Building materials: all are natural and local available materials including stone and mud for wall construction and mud, tree branch, timber/wood, slate for flat hidmo roof and lime, straw and animal dung for wall and floor finish.

Thick walls of cut stone: hidmo dwellings unit is in the shape of a rectangle, enclosed with masonry stone walls whose thicknesses vary between $50 \mathrm{~cm}-60 \mathrm{~cm}$. The mud mortar commonly used to bind the courses of stone ripraps that used as filler and the stone courses. On sloped grounds, buildings are erected by adapting the site using terraced roof with the same level of as of the back yards and the thick walls use as a thermal mass.

Fenestration: The only windows are rectangular and/or sometimes triangular equally spaced attic level small windows used for ventilation and lighting and the doors are human scale with rectangular thick double wooden doors with metal percussion. Due to the cross ventilation and wind flow from the door a Venturi effect will be created which helps to ventilate the rooms. [15]

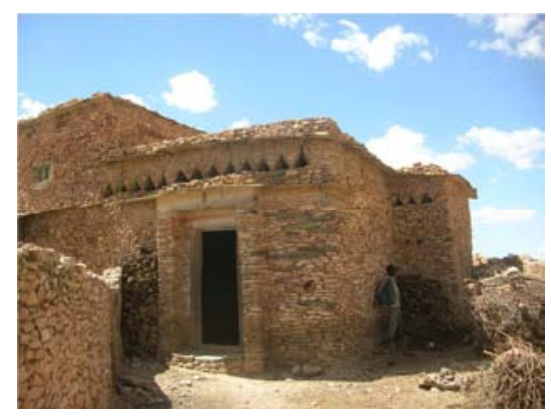

Figure 8. Fenestrations

Earthen flat roof called Hidmo: Hidmo dwellings are covered with earthen flat roofs coated with water-resistant soil in gabled shape position. [7] The ceilings are wattle and daub; tree branch also used before the mud and then soil coating. The ceiling is absolutely stunning hand carved wood arranged in an artistic geometric patterns usually looks like
Fishbone shaped. It is common to see a slate closed half pot on the earthen flat roof for the lighting, smoke escapes and ventilation purpose. [11] When the rural dweller finds that the ceiling is dripping, he/she climbs the rooftop and mends the mud/soil coating by replacing with new mud. Generally the flat hidmo roof is made of mud, wooden ceiling, filler of tree branch and wide overhanging stone, slate as eave which protects the wall from rain water percolation. [1]

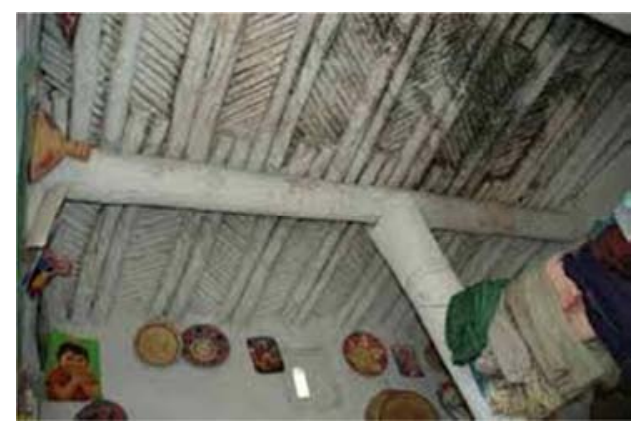

Figure 9. The fishbone shaped wattle and daub ceiling.

Finishing schedule: For the flooring purpose, the earth is properly filled and consolidated with a mix of mud and animal dung for finishing. For interior wall before the painting process surface is prepared and painted white or off-white color made from local available crushed local limestone (nora), whereas the semi-dressed or dressed exterior stone wall left unpolished.

Monkey head construction method: The indigenous distinct construction methodology of Tigrai is called the 'monkey head' construction techniques. It takes its name from the use of protruding, rounded off wooden cross members ("dowels") to bind together horizontal layers of wood between layers of a stone or course in a wall. The exceptional monkey head technique was designed to bind and strengthened the wall and provides support at narrow intervals with long squared timbers and short round crosspieces hold these in place, while making use of available resources (stone, wood and soil $/$ mud). The protruding sections of the cross pieces are termed the "monkey-heads" and this method of construction were applicable in the vernacular Tigrai hidmo house. [3].

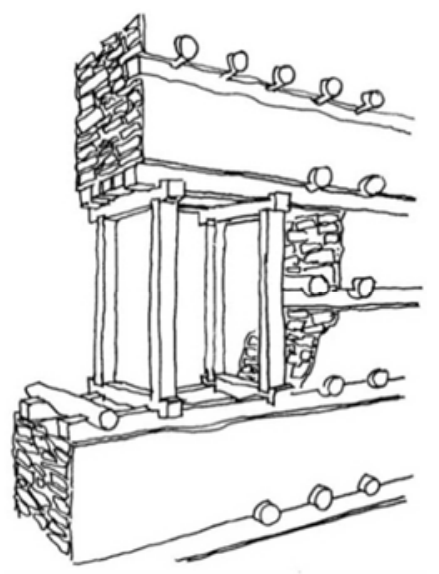

Figure 10. Monkey head construction techniques. 
Traditional chimney: a smoke escapes and natural light entry point in the flat roof is made of half water pot found in the main kitchen and the living area serves basically as a chimney.

Interior space: A good family house would have three free standing buildings; the storage where the family crop is kept, the living room where the family spent most of the times and used as gathering and sleeping area, the kitchen where the food cooked for the family, sometimes could be a round stone house connected with grain store or living room has a conical roof covered with straws. Sometimes all the rooms could double as bedrooms function. The interior space is articulated by mud made furnishes serve as setting bench which is raised plat form runs along walls called medeb and another slightly higher platform built adjacent to the wall and means to serve as a bed called niedi and a variety of this kind of bed called niedi meraut literally a bed for married couples has a privacy either by its height from the floor or defined by dwarf wall. The interior wall decorated by recesses called niche which commonly used as special shelf. [3].

Column (Andi): The wooden column/pillar supports the flat hidmo roof is placed in a functional way without much symmetry. It appears that their spacing is more a function of the length and size of the beams used to support the roof. [3].

Staircase: On the outside of the houses they have beautifully built stone steps leading to the roof where the roof is used for many purposes, including sheep and goat area or as a hay/straw store.

Sustainability aspects: Elements of the Tigrai vernacular housing and their sustainability features and applications are discussed as tabulated in Table 2.

Table 2. Sustainability aspects of the hidmo house.

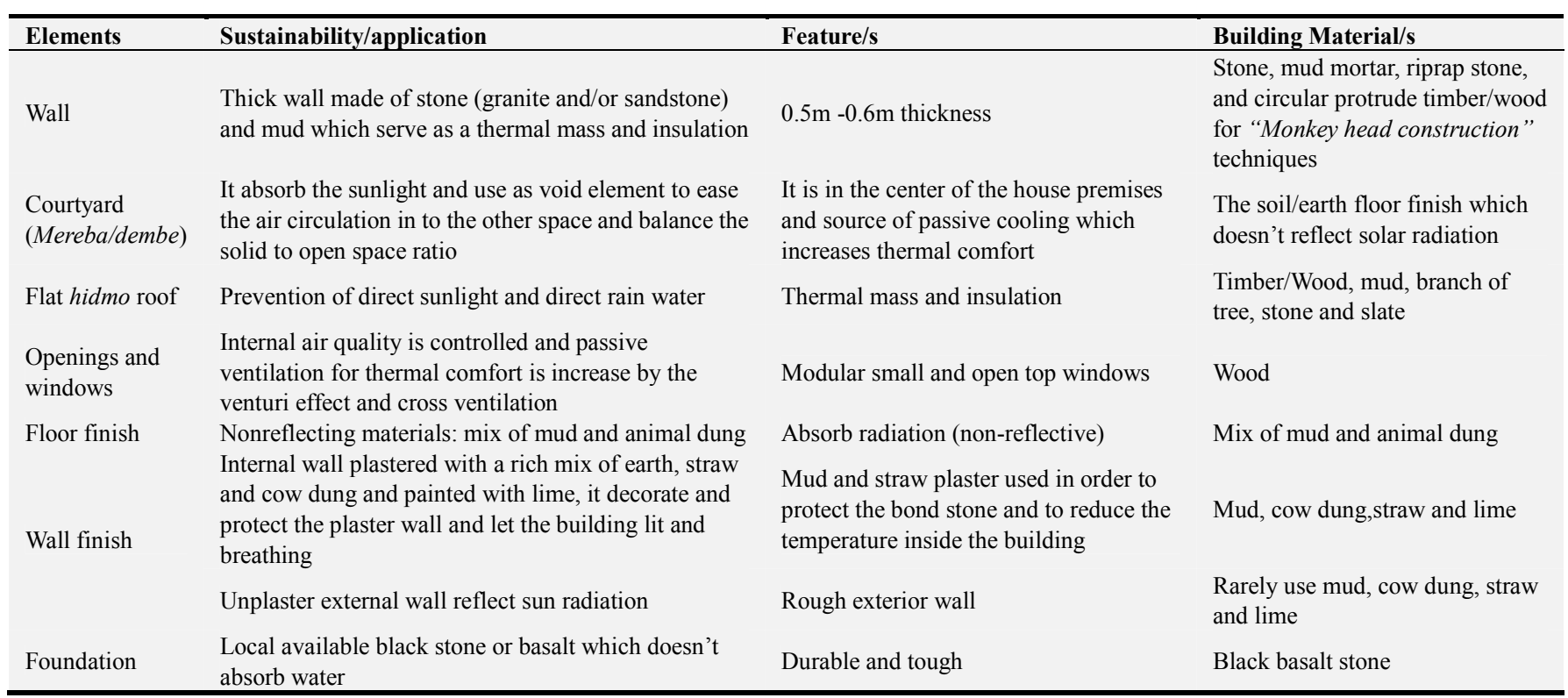

\section{Conclusions}

Tigrai vernacular houses were more than thousands years old with not much change and still in use in the entire villages of the region. So evaluation, apprising and classifying the architectural elements, features and standardizing the housing typology is less known and studied. Tigrai region, Ethiopia is among the most ancient regions in the validity of indigenous civilization, and this is reflected in its vernacular architecture especially in its stone housing construction.

The Tigrai vernacular housing architectural spaces have three patters the open space, semi-open space and the closed spaces. The open spaces include the heart of the sustainable design element, such as courtyard (dembe) and the terrace of the flat hidmo roof (nahsi). The semi-open spaces which are an intermediate space between the open space and closed space defined by wooden column and flat roof, which include important spots of the housing such as the entrance, porch and pergola (afgebela/gebela). The livable space which is common in all the housing typology are the closed space with one to two stories which includes importance spaces like living, dining, kitchen and store areas locally called mediribet and wushate respectively. The most astonishing construction system of hidmo house is the Monkey head construction system which peculiar to Tigrai architecture specifically for Akumite civilization period and still practiced in Tigrai rural areas.

The Typical housing of the vernacular architecture or Stone hidmo housing is responding the sustainability concepts of architecture in many cases including:

a). Local traditional building material (sustainable building material):less energy in all aspects.

b). Passive cooling and heating due to venture effect (Fenestration provide lighting and ventilation).

c). Less reflecting facade treatment.

d). Optimized and responding shape of plan and form.

e). Long wall side is facing towards North in most cases.

f). Small modular top opening or fenestrations for control in and out of air and lighting hence to maintain thermal comfort 
besides of the thick wall.

\section{Acknowledgements}

The author wishes to express his gratitude to all people who have participated directly and indirectly during the research work and special thanks goes to my spouse Feven Tekeste.

\section{References}

[1] Diane E. Lyons,(2007) Building Power in Rural Hinterlands: An Ethnoarchaeological Study of Vernacular Architecture in Tigray, Ethiopia, Journal of Archaeological Method and Theory, Vol. 14, No. 2 (June, 2007), pp. 179-207.

[2] Doerr Architecture, (2011). Definition of Sustainability and the Impacts of Building.

[3] Gebremedhin, N. 1977: "Some traditional types of housing in Ethiopia”.

[4] Lawrence, R. J. (2006) "Learning from the Vernacular: Basic Principles for Sustaining Human Habitats", in Asqiuth, L. and Vellinga, M. (eds) Vernacular Architecture in the Twenty-First Century: Theory, Education and Practice. Taylor and Francis, New York.

[5] Marino luigi, lodino michele, 1999, la casa tradizional nei villaggi della giordania, cierre edizioni, Italy.
[6] Million Eyob 2012 Asmara: Hub of Ancient and Contemporary Architecture (Part II).

[7] Nobuhiro Shimizu (2016) An Analysis of the Construction Method of Emperor Yohannes IV's Buildings in Tigray Region, Ethiopia

[8] Oliver, P. (2006b) Built to Meet Needs; Cultural Issues in Vernacular Architecture. Elsevier Ltd, London.

[9] Rapoport, A. (1969) House Form and Culture. Prentice-Hall: Englewood Cliffs, NJ.

[10] Rumi Okazaki 2014, A study on the formation of an imperial city in Tigray, Ethiopia, at the turn of the 20th Century: Mekelle during and after the region of Yohannes IV pp. 1-7

[11] Jill last (1987) Ethiopians and the house they live in.

[12] http://www.ethiopia.gov.et/statetigray.

[13] https://en.wikipedia.org/wiki/Tigray_Region.

[14] https://archiabyssniya.wordpress.com/art-architecture/artthoug ht/artarchitectureafrican-art/traditional-house-tigray/.

[15] https://en.wikipedia.org/wiki/Venturi_effect.

[16] https://www.flickr.com/photos/geobulga/sets/7215762370087 2119. 